\title{
Anatomical Variation of Facial Artery Branch: A Case Report
}

\author{
Guilherme Raulino Brasil ${ }^{1}$ Josete Mazon ${ }^{2}$ \\ ${ }^{1}$ Department of Odontology, Academic Unit of Health Sciences, \\ Universidade do Extremo Sul Catarinense (UNESC), Criciúma, SC, Brazil \\ ${ }^{2}$ Department of Health Sciences, Universidade Federal de Santa \\ Catarina (UFSC), Araranguá, SC, Brazil \\ J Morphol Sci 2018;35:218-220.
}

\begin{abstract}
Address for correspondence Josete Mazon, PhD, Departamento de Ciências da Saúde, Universidade Federal de Santa Catarina (UFSC), Unidade Jardim das Avenidas. R. Gov. Jorge Lacerda, 3201 Urussanguinha, CEP 88906-072, Araranguá, SC, Brazil (e-mail: jomazoncmf@gmail.com).
\end{abstract}

Abstract
Keywords
- facial artery
- superior labial artery
- anatomical variation
- branching pattern
- fillers

Introduction The facial artery and its branches are the major vessels that supply blood to the face region. This artery and its branches can present variations in path and branching pattern and thus complicate the location of these arteries during invasive procedures. There is still a great need to inform and clarify the variant or unusual organization of the display of these arteries.

Case Report During the dissection of the head and neck region of a cadaver, an anomalous branch of the unilateral facial artery was observed in the superior labial artery. Conclusion The lack of knowledge about the possible pathways of the facial artery and its branches can lead to errors in surgical procedures or fillers, causing severe complications to the facial structures.

\section{Introduction}

The blood supply of the face in humans comes mainly from the facial artery (FA), which branches from the external carotid artery. FA is one of the anterior arteries of the External carotid artery in conjunction with Lingual and Superior thyroid. The FA has a tortuous form and ascends toward the nasal alaeque along the main Zygomaticus muscle and Risorius muscle and superficially with the Buccinator muscle and Levator anguli oris muscle, has variable relation with the Levator labii superioris muscle. In this way, the FA ascends to the base of the nose, called the angular artery, and emits perforating branches to the facial muscles along its way. ${ }^{1}$

The anatomical variation is a morphological difference presented by the population, within normality. ${ }^{2}$ The discovery of anatomical variations is an important landmark in the study of anatomy, because it supports the interpretation of many situations in which treatments require invasive approaches by health professionals. ${ }^{3}$

These anatomical vascular variations are essential for the diagnosis and surgical approaches in the head region, ${ }^{4}$

received

September 19, 2017

accepted

September 6, 2018

published online

November 6, 2018

$10.1055 / \mathrm{s}-0038-1675570$. ISSN 2177-0298. particularly to minimize hemorrhagic and postoperative complications. ${ }^{5}$ Therefore, we report the case of a male cadaver with this variation with the aim of broadening the knowledge and assisting clinicians and surgeons with the interpretation of images, diagnosis, treatment, and surgery.

\section{Case Report}

During dissection of the head and neck region by undergraduate students in dentistry, a unilateral anatomical variation was observed in the standard and branching pathway of the FA of a 28-year-old male cadaver. On the left side of the head, the FA exhibits a short ascending path branching into the inferior labial artery (ILA) and superior labial artery (SLA) (-Fig. 1). While describing the right region of the face of the same cadaver, we found another pattern of branching of the FA. We observed the formation of the ILA and after its origin, the ascending path of the facial artery becomes more tortuous and more medial in relation to the other paths described. Near the midline, the ramification of the SLA arises in the region of the canine alveolar eminence, a rare event (and variant). Continuing its ascendancy and just above

Copyright @ 2018 by Thieme Revinter

Publicações Ltda, Rio de Janeiro, Brazil

License terms

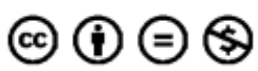




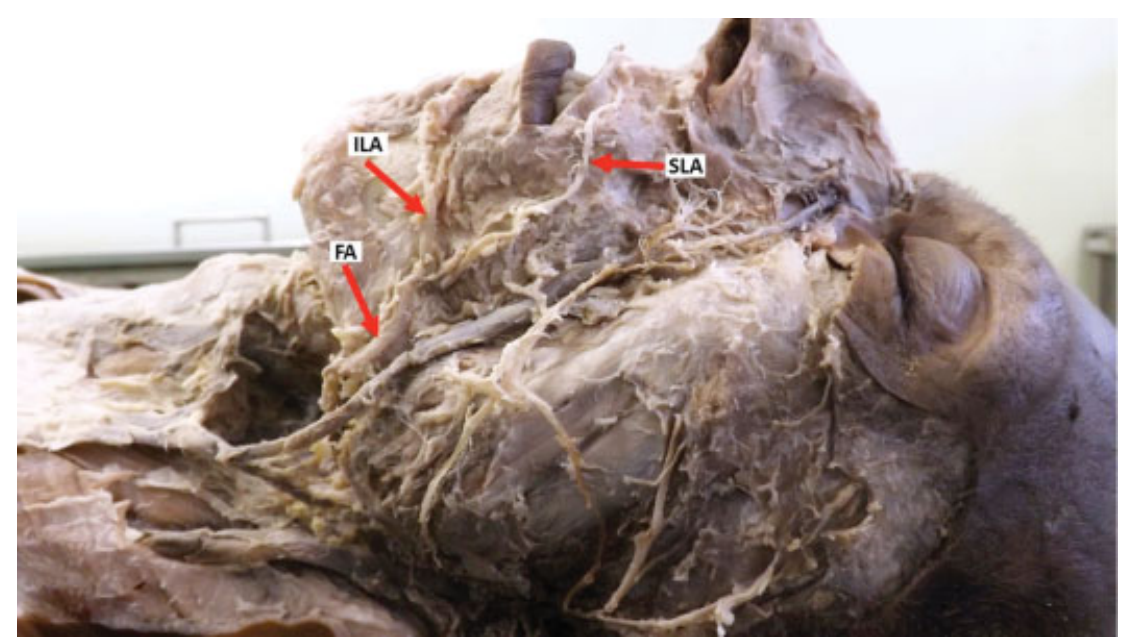

Fig. 1 Branch of the facial artery (FA) on the left side of the face. Abbreviations: ILA, inferior labial artery; SLA, superior labial artery.

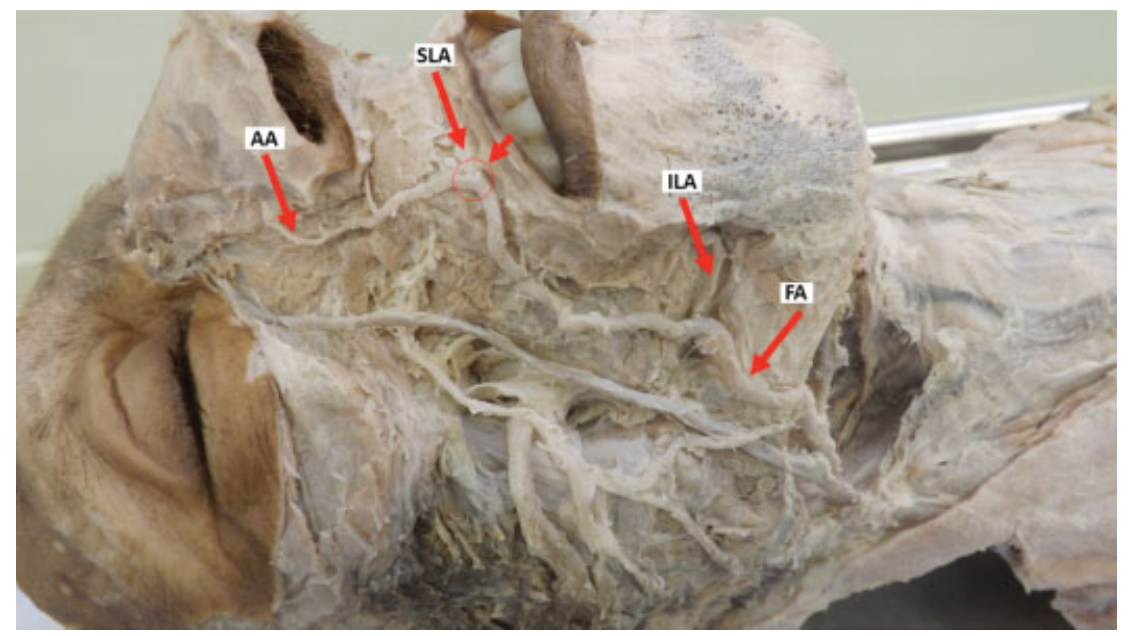

Fig. 2 Branching pattern of the facial artery (FA) on the right side of the face different from that found on the left side of the face. Abbreviations: AA, angular artery; ILA, inferior labial artery; SLA, superior labial artery.

the SLA, the FA gives rise to the Alar artery (-Fig. 2). We also observed that the angular artery (AA) varied from the standard path and had a smaller apparent caliber in comparison with those presented in the classical literature.

\section{Discussion}

The case reported shows variations observed in the trajectory and branching of the artery in a male Caucasian cadaver. The variations of anatomical shown by various researches in human cadavers report that the vascular branches of the mentum region and mainly labial have numerous individual configurations. ${ }^{6}$ Changes in diameter, trajectory, dominance, and symmetry can be seen in these cadavers. ${ }^{7-9}$

Variations on the FA include the rare absence of the artery, ${ }^{8}$ different routes and types of branching, ${ }^{7,9,10}$ and pattern variation of the dominant side. ${ }^{11}$

However, the differential unilateral variation reported in this study concerning the branches of the FA and the SLA and observed in the same cadaver is reported for the first time.
The FA is extremely tortuous in its path; this often facilitates its perforation at the clinic setting, which causes bruising. ${ }^{3}$ Clinical studies report severe cases of arterial occlusion related to the application of fillers in the practice of facial aesthetics. ${ }^{8,12}$ For this reason, it is important to consider the branches emitted by this artery, and the extension of the vascularized area, because the consequences of its occlusion, spasm or compression can lead to necrosis, ischemia, and scarring in the entire area that depends on it. $^{12,13}$

Therefore, the dissemination of knowledge of the different anatomical patterns exhibited by these vessels is extremely important, since the FA is the main vessel of irrigation of the face ${ }^{1}$ and has considerable clinical importance, especially in the surgical and aesthetic areas. ${ }^{13}$

\section{References}

1 Gray H. Anatomia. Rio de Janeiro: Guanabara Koogan, 1988.

2 Rajani S. An investigation of virgin variation of branching pattern of ECA and CCA: a case report. Journal of Morphological Sciences 2017;34(01):10-12 
3 Itacarambi AA, Dos Santos GL, Oliveira IG, Guimarães NN. Análise das variações anatômicas mais frequentes descritas entre 2010 e 2012. Revista Eletrônica de Educação da Faculdade Araguaia 2014;5:114-122

4 Poynter CWN. Congenital anomalies of the arteries and veins of the human body with bibliography. Lincoln. The University Studies of the University of Nebraska 1992;22:1-106

5 Hayashi N, Hori E, Ohtani Y, Ohtani O, Kuwayama N, Endo S. Surgical anatomy of the cervical carotid artery for carotid endarterectomy. Neurol Med Chir (Tokyo) 2005;45(01):25-29, discussion 30 10.2176/nmc.45.25

6 Mağden O, Edizer M, Atabey A, Tayfur V, Ergür I. Cadaveric study of the arterial anatomy of the upper lip. Plast Reconstr Surg 2004; 114(02):355-359

7 Al-Hoqail RA, Meguid EM. Anatomic dissection of the arterial supply of the lips: an anatomical and analytical approach. J Craniofac Surg 2008;19(03):785-794
8 Paixão MP. Conheço a anatomia labial? . Implicações para um bom preenchimento. Surgical and Cosmetic Dermatology 2015;7(01): 10-16

9 Ricbourg B. [Blood supply of the lips]. Ann Chir Plast Esthet 2002; 47(05):346-356

10 Crouzet C, Fournier H, Papon X, Hentati N, Cronier P, Mercier P. Anatomy of the arterial vascularization of the lips. Surg Radiol Anat 1998;20(04):273-278

11 Tansatit T, Apinuntrum P, Phetudom T. A typical pattern of the labial arteries with implication for lip augmentation with injectable fillers. Aesthetic Plast Surg 2014;38(06):1083-1089

12 Tamura BM. Anatomia da face aplicada aos preenchedores e à toxina botulínica-Parte II. Surgical \& Cosmetic Dermatology 2010;4:291-303

13 Garcia de Mitchell CA, Pessa JE, Schaverien MV, Rohrich RJ. The philtrum: anatomical observations from a new perspective. Plast Reconstr Surg 2008;122(06):1756-1760 